\title{
PROTO-PLANETARY DISK CHEMISTRY RECORDED BY D-RICH ORGANIC RADICALS IN CARBONACEOUS CHONDRITES
}

\author{
Laurent Remusat $^{1,4}$, François Robert ${ }^{1}$, Anders Meibom $^{1}$, Smail Mostefaoui $^{1}$, Olivier Delpoux ${ }^{2}$, Laurent Binet $^{2}$, \\ Didier Gourier ${ }^{2}$, AND Sylvie Derenne ${ }^{3}$ \\ ${ }^{1}$ Laboratoire de Minéralogie et Cosmochimie du Muséum, UMR7202, Muséum National d'Histoire Naturelle, 57 rue Cuvier, Case 52, 75005 Paris, France \\ ${ }^{2}$ Laboratoire de Chimie de la Matière Condensée de Paris, UMR CNRS 7574, ENSCP, 11 rue Pierre et Marie Curie, 75005 Paris, France \\ ${ }^{3}$ Laboratoire de Géochimie organique et minérale de l'environnement, UMR CNRS 7618, BioEMCo, UPMC, 4 place Jussieu, 75252 Paris Cedex 05 , France \\ Received 2008 May 6; accepted 2009 April 6; published 2009 June 8
}

\begin{abstract}
Insoluble organic matter (IOM) in primitive carbonaceous meteorites has preserved its chemical composition and isotopic heterogeneity since the solar system formed $\sim 4.567$ billion years ago. We have identified the carrier moieties of isotopically anomalous hydrogen in IOM isolated from the Orgueil carbonaceous chondrite. Data from high spatial resolution, quantitative isotopic NanoSIMS mapping of Orgueil IOM combined with data from electron paramagnetic resonance spectroscopy reveals that organic radicals hold all the deuterium excess (relative to the bulk IOM) in distinct, micrometer-sized, D-rich hotspots. Taken together with previous work, the results indicate that an isotopic exchange reaction took place between pre-existing organic compounds characterized by low $\mathrm{D} / \mathrm{H}$ ratios and $D$-rich gaseous molecules, such as $\mathrm{H}_{2} \mathrm{D}^{+}$or $\mathrm{HD}_{2}{ }^{+}$. This exchange reaction most likely took place in the diffuse outer regions of the proto-planetary disk around the young Sun, offering a model that reconciles meteoritic and cometary isotopic compositions of organic molecules.
\end{abstract}

Key words: astrochemistry - solar system: general

\section{INTRODUCTION}

Carbonaceous chondrites are considered among the most primitive objects in the solar system. For all but the most volatile elements, the elemental bulk composition of these meteorites is very close to that of the Sun (Lodders 2003). Furthermore, carbonaceous chondrites can contain up to $4 \mathrm{wt} \%$ of organic matter, the main fraction of which is recovered as an insoluble macromolecular component (Pizzarello et al. 2006). This insoluble organic matter (IOM) primarily consists of small aromatic units (with up to six rings) linked by branched aliphatic linkages shorter than seven carbon atoms, resulting in a high degree of crosslinking (Hayatsu et al. 1980; Gardinier et al. 2000; Sephton et al. 2004; Remusat et al. 2005a; Remusat et al. 2005b).

Another important characteristic of the meteoritic IOM is the systematic enrichment in deuterium relative to terrestrial samples (Robert \& Epstein 1982). Reported bulk values are comprised between $650 \%$ and 5600\% (Robert \& Epstein 1982; Kerridge 1983; Alexander et al. 2007) depending on the meteorite. This high enrichment was interpreted as the result of interstellar-like processes (Yang \& Epstein 1983) occurring in cold and irradiated environments like dense molecular clouds (Sandford et al. 2001) where ion/molecule or gas/grain reactions could occur. Furthermore, the IOM is isotopically heterogeneous, as demonstrated by recent compound-specific hydrogen isotopic studies (Wang et al. 2005; Remusat et al. 2006) as well as observations of D-rich hotspots in NanoSIMS ion microprobe images (Busemann et al. 2006, and Figure 1 of this paper). Understanding the origin of this heterogeneity represents a fundamental challenge with implications for the origin, production mechanism(s), and distribution of organics in the interstellar medium (ISM) and in the proto-planetary disk around the young Sun.

\footnotetext{
${ }^{4}$ Current address: Geological and Planetary Science Division, California Institute of Technology, Pasadena, CA 91125, USA.
}

Compound specific ${ }^{13} \mathrm{C} /{ }^{12} \mathrm{C}$ measurements performed on $\mathrm{CI}$ and CM IOMs have been interpreted as the result of the superimposition of parent body processes and radical chemistry in irradiated interstellar-like environments (Sephton \& Gilmour 2000). This is consistent with previous models, implying that IOM was made of highly enriched interstellar precursors equilibrated with depleted solar hydrogen-rich compounds in the gas phase or on the parent body. These observations are in contrast with recent compound-specific $\mathrm{D} / \mathrm{H}$ measurements, indicating that IOM might be a solar product which has undergone Denrichment by exchange with an enriched proto-solar ionized gas phase (Remusat et al. 2006). The theoretical occurrence of D-rich ionized gas in the protostellar disks has been recently demonstrated (Ceccarelli \& Dominik 2005; Qi et al. 2008), revealing that interstellar-like conditions may occur in the early solar system nebula and hence reinforcing the hypothesis of $D$ enrichment taking place into the protosolar nebula. At present, as stated by Alexander et al. (2007), "the evidence for and against ISM or nebular origins is equivocal" as the isotopic trends observed are difficult to interpret with the models proposed so far.

This paper presents the extension of our work on the isotopic composition of chondritic IOM. We are now able to prove quantitatively that the organic radicals constitute the $D$-rich carrier in the $D$-rich hot spots observed in Orgueil IOM as was already suggested by Gourier et al. (2008) based on the chemical and isotopic properties of organic radicals detected in Orgueil IOM. This result reconciles the occurrence of $D$-rich hot spots with our model on the influence of the molecular structure of the IOM on its isotopic heterogeneity.

\section{METHODS}

We have acquired NanoSIMS images of IOM of Orgueil, Murchison, and Kainsaz (carbonaceous chondrites) along with $600^{\circ} \mathrm{C}$ pyrolyis residue of Murchison IOM with the Cameca NanoSIMS 50 installed at LEME, Museum National d'Histoire 


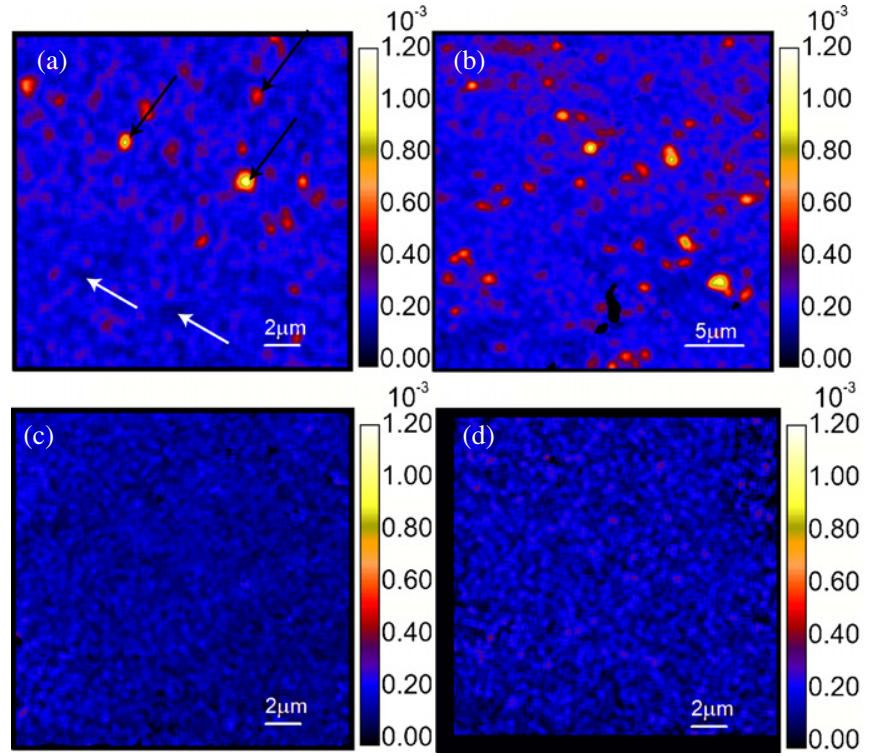

Figure 1. D/H isotopic ratio NanoSIMS image of Orgueil (a), Murchison (b), Kainsaz (c) IOMs, and a $600^{\circ} \mathrm{C}$-pyrolysis residue of Murchison IOM (d). Each image is covering a surface of $20 \times 20 \mu \mathrm{m}^{2}$ except (b) that is covering $40 \times 40 \mu \mathrm{m}^{2}$. (a) and (b) exhibit D-rich hotspots (black arrows in (a)) that can be eliminated below a $\mathrm{D} / \mathrm{H}$ threshold. D-poor regions (white arrows in (a)) are also observed and are referred to as coldspots. (a) is consistent with the prediction of the distribution of D-rich radicals in Orgueil IOM, from both EPR and pulsed EPR data.

Naturelle of Paris, France. Orgueil (CI1) and Kainsaz (CO3) samples were provided by the Museum National d'Histoire Naturelle, Paris, France. Murchison (CM2) meteorite was provided by Smithonian Institution, Washington DC, USA. IOM was isolated by classical $\mathrm{HF} / \mathrm{HCl}$ demineralization (Remusat et al. 2005a). After several solvent extractions (water, acetone, methanol/dichloromethane), bulk meteorite powder was subjected to an $\mathrm{HCl}$ leaching for $24 \mathrm{hr}$ and after neutralization to a $24 \mathrm{hr} \mathrm{HF} / \mathrm{HCl}$ dissolution of silicates. Finally, the acid residue was extracted with acetone and $\mathrm{MeOH} / \mathrm{CH}_{2} \mathrm{Cl}_{2}$ mixture $(2 / 1 \mathrm{v} / \mathrm{v})$. Murchison IOM was pyrolyzed at $600^{\circ} \mathrm{C}$, and the residue constitutes the sample "Murchison $600^{\circ} \mathrm{C}$."

For NanoSIMS analyses, the IOMs were pressed into clean Indium foil and the surface was subsequently coated with gold. A focused primary beam of $\mathrm{Cs}^{+}$ions $(1.8 \mathrm{pA})$ with a diameter of ca. $100 \mathrm{~nm}$ was scanned over areas of $20 \times 20 \mu \mathrm{m}^{2}$ on the surface of IOM, defining images of $256 \times 256$ pixels at a raster speed of $1 \mathrm{~ms}$ pixel ${ }^{-1}$. The secondary ions $\mathrm{H}^{-}, \mathrm{D}^{-}$, ${ }^{12} \mathrm{C}^{-},{ }^{16} \mathrm{O}^{-}$, and ${ }^{12} \mathrm{C}^{14} \mathrm{~N}^{-}$were collected in a combined analysis mode at a mass resolution of ca. $6000(M / \Delta M)$, which is enough to resolve potential molecular interferences. A weak magnetic field allowed the simultaneous detection of $\mathrm{H}^{-}$and $\mathrm{D}^{-}$, and a stronger magnetic field allowed the simultaneous detection of the other isotopes. This enabled us to record all images without moving the sample. The instrumental fractionations for isotopic and elemental ratios were determined using a standard charcoal, which was measured several times each day. Moreover, prior to data collection, each sample was exposed to presputtering with a high $\mathrm{Cs}+$ current for 20 minutes in order to remove surface contamination, the gold coating, and to reach sputtering equilibrium. Data were reduced using the L'IMAGE ${ }^{\circledR}$ software developed by L. Nittler, Carnegie Institution, Washington DC, USA.

Particles such as their pixels fill the condition $\mathrm{l}(\mathrm{D} / \mathrm{H})$ $(\mathrm{D} / \mathrm{H})_{\text {bulk }} \mathrm{l} / \sigma>2.5$ were defined as regions of interest (ROIs), with $\sigma$ being the statistical error for each pixel. Moreover, a minimum size of 50 pixels $\left(0.3 \mu \mathrm{m}^{2}\right)$ was set for ROIs definition. Each ROIs defined by this way constitutes a "hot spot." Each ratios obtained from L'IMAGE ${ }^{\circledR}$ was subsequently corrected for instrumental mass fractionation.

\section{RESULTS AND DISCUSSION}

Figure 1 shows D/H images of Orgueil, Murchison, Kainsaz IOMs, and "Murchison $600^{\circ} \mathrm{C}$ " sample. The most striking observation is the occurrence of small areas highly enriched in D compared to bulk value, defining D-rich hot spots (Busemann et al. 2006). They exhibit $\mathrm{D} / \mathrm{H}$ from $412 \pm 31$ to $723 \pm 25 \times$ $10^{-6}$ compared to $\mathrm{D} / \mathrm{H}_{\text {bulk }}=223 \pm 2.3 \times 10^{-6}$ for Orgueil IOM and from $443 \pm 34$ to $946 \pm 28 \times 10^{-6}$ compared to $\mathrm{D} / \mathrm{H}_{\text {bulk }}=265 \pm 8 \times 10^{-6}$ for Murchison IOM. Their average size is around $1 \mu \mathrm{m}$ in diameter. These hot spots are widespread all over the surface of the sample, without any spatial pattern. These observations are consistent with previous reports of Drich hot spots in IOM of CI, CM, and CR (Busemann et al. 2006; Robert et al. 2006). In contrast, Kainsaz IOM which is known to have been subjected to $350^{\circ} \mathrm{C}$ (Bonal et al. 2007) and Murchison $600^{\circ} \mathrm{C}$ does not exhibit any hot spots (Figure 1). It thus appears that the material bearing the high D-enrichment is sensitive to high temperature. It also must be noted that bulk $\mathrm{D} / \mathrm{H}$ ratios determined by NanoSIMS are systematically lower than values determined by classical stepped pyrolysis. This is due to adsorbed water with low $\mathrm{D} / \mathrm{H}$ ratio that was not outgased at $300^{\circ} \mathrm{C}$ previously to ion probe analyses-in contrast to stepped pyrolysis analyses.

Organic nanoglobules have been reported to occur in CM and CI carbonaceous chondrites (Garvie \& Buseck 2004). These objects seem to be associated with high enrichment in ${ }^{15} \mathrm{~N}$ and D (Nakamura-Messenger et al. 2006). Their size range from 0.2 to $1.6 \mu \mathrm{m}$ in diameter, so one might question if the Drich hot spots we observe might be related to these globules. The D-rich hot spots we described cannot be nanoglobules because these carbonaceous spheres have by definition voids in their centers. Garvie and Buseck (2004) measured the wall thickness of several globules in Tagish Lake and found that the wall is maximum $0.2 \mu \mathrm{m}$ thick and so voids may be as large as $0.6 \mu \mathrm{m}$ in diameter. Then, $\mathrm{C}$ and $\mathrm{H}$ images should exhibit a tiny hole in the middle of the D-rich hot spots. This is not the case and so we conclude that the D-rich hot spots we describe are not related to the nanoglobules. It may be possible that they have been destroyed by our sample preparation, as the previous observations were made only on untreated bulk carbonaceous chondrites samples.

It appears from our observations that the micron scale Disotopic anomaly in IOM is related to organic moieties that are absent in thermally processed samples and heterogeneously distributed to constitute the D-rich hot spots. Organic radicals fulfill these two properties in the IOM of hydrated chondrites, and their concentration is very low in Kainsaz IOM (Remusat et al. 2008). We thus propose that organic radicals in IOM are responsible for the occurrence of the D-rich hot spots observed in Orgueil IOM, which is reasonable if one compares the estimated volume fraction ( $\sim 20 \%$, Binet et al. 2002) of IOM containing radicals with the fraction of D-rich hotspots $(15 \%-38 \%)$ in Orgueil IOM imaged by NanoSIMS (Figure 1).

EPR spectroscopy shows that, for instance in Orgueil IOM, the relative abundance of hydrogen associated with organic radicals is: $\mathrm{H}_{\text {radicals }} / \mathrm{H}_{\text {total }}=3.6( \pm 1.2) \times 10^{-3}$ (Binet et al. 2002; Gourier et al. 2008). In contrast with terrestrial organic samples, 
Table 1

NanoSIMS Image Analysis Results for Orgueil IOM

\begin{tabular}{lccccc}
\hline \hline Threshold & $(\mathrm{D} / \mathrm{H})_{\text {radical-free }}$ & $\begin{array}{c}(\mathrm{D} / \mathrm{H})_{\text {radicals }} \\
(\text { From EPR })\end{array}$ & $\mathrm{H}_{\text {radicals }} / \mathrm{H}_{\text {total }}$ & $\begin{array}{c}\mathrm{H}_{\text {radicals }} / \mathrm{H}_{\text {total }} \\
\text { (From EPR) }\end{array}$ & $\begin{array}{c}\mathrm{H}_{\text {radicals }} / \mathrm{H}_{\text {total }}(\text { From } \\
\text { EPR Monoradicals Only) }\end{array}$ \\
\hline $278 \times 10^{-6}$ & $199 \pm 2 \times 10^{-6}$ & $15000 \pm 5000 \times 10^{-6}$ & $1.65 \pm 0.55 \times 10^{-3}$ & $3.6 \pm 1.2 \times 10^{-3}$ & $2.16 \pm 0.72 \times 10^{-3}$ \\
$228 \times 10^{-6}$ & $180 \pm 2 \times 10^{-6}$ & $15000 \pm 5000 \times 10^{-6}$ & $2.87 \pm 0.96 \times 10^{-3}$ & $3.6 \pm 1.2 \times 10^{-3}$ & $2.16 \pm 0.72 \times 10^{-3}$ \\
\hline
\end{tabular}

Notes. The Measured Bulk D/H Ratio is $223( \pm 2) \times 10^{-6}$. Hotspots Were Removed in the Calculation of the Mean $(\mathrm{D} / \mathrm{H})_{\text {radical-free }}$ using the Threshold Value Indicated in the First Column. These Thresholds are Defined Relative to the Gaussian Distribution of D/H Ratios from Individual Pixels in each Image, which Defines one Standard Deviation as $\approx 25 \times 10^{-6}$.

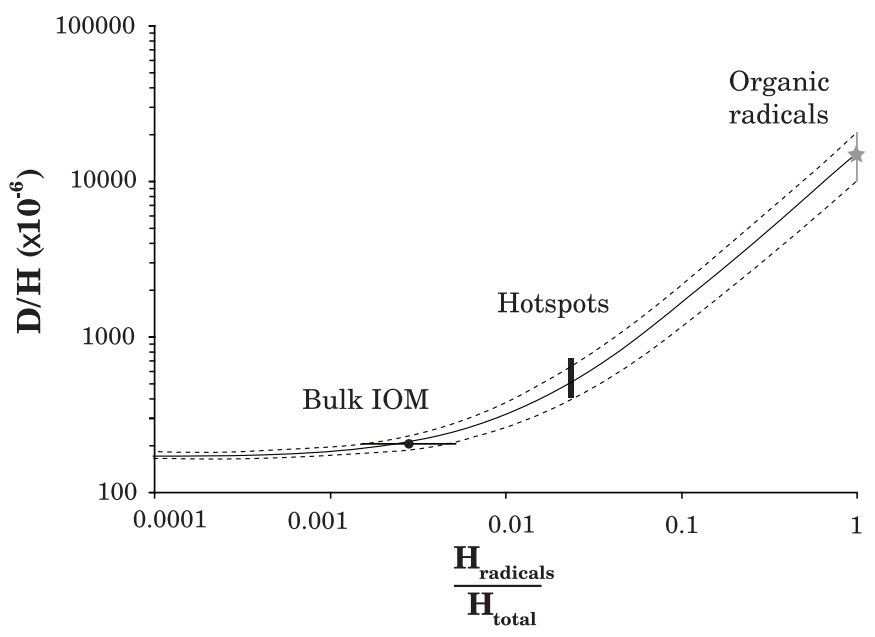

Figure 2. Theoretical mixing curves of isotopic end members in the IOM. The mixing calculation is performed for EPR data: i.e., organic radicals with a $\mathrm{D} / \mathrm{H}=15000( \pm 5000) \times 10^{-6}$ for $\mathrm{H}_{\text {radicals }} / \mathrm{H}_{\text {total }}=1$ and $\mathrm{a} \mathrm{H}_{\text {radicals }} / \mathrm{H}_{\text {total }}=$ $2.16( \pm 0.72) \times 10^{-3}$ for the bulk D/H IOM. Gray star represents EPR data. NanoSIMS data (bars and dot) are shown in black. Within error they overlap with the calculated mixing curve, demonstrating that organic radicals account for the D-anomaly in hotspots.

organic radicals in Orgueil IOM are heterogeneously distributed (Binet et al. 2002) with a local concentration of $\left(\mathrm{H}_{\text {radicals }} /\right.$ $\left.\mathrm{H}_{\text {total }}\right)_{\text {loc }}=21.6( \pm 7.2) \times 10^{-3}$. Pulsed-EPR spectroscopy shows that the $\mathrm{D} / \mathrm{H}$ ratio of these radicals, $(\mathrm{D} / \mathrm{H})_{\text {radicals, averages }}$ $15000( \pm 5000) \times 10^{-6}$ (Gourier et al. 2008). By using a mass balance equation $(\mathrm{D} / \mathrm{H})_{\mathrm{rad}-\mathrm{rich}}=(\mathrm{D} / \mathrm{H})_{\text {radicals }} \times\left(\mathrm{H}_{\text {radicals }} /\right.$ $\left.\mathrm{H}_{\text {total }}\right)_{\text {loc }}+(\mathrm{D} / \mathrm{H})_{\text {radical-free }} \times\left(1-\left(\mathrm{H}_{\text {radicals }} / \mathrm{H}_{\text {total }}\right)_{\text {loc }}\right)$, we can predict that, in the radical-rich regions, the $\mathrm{D} / \mathrm{H}$ ratio should be $(\mathrm{D} / \mathrm{H})_{\text {rad-rich }} \geqslant 570 \times 10^{-6}$. $(\mathrm{D} / \mathrm{H})_{\text {radical-free }}$ used in this equation is calculated thanks to the first-order assumption that IOM consists of a mixture between radical-rich and radical-free organic IOM (Figure 2). Then, the bulk D/H ratio of the IOM can also be expressed by the following mass balance equation: $(\mathrm{D} / \mathrm{H})_{\text {bulk }}=(\mathrm{D} / \mathrm{H})_{\text {radicals }} \times\left(\mathrm{H}_{\text {radicals }} / \mathrm{H}_{\text {total }}\right)+(\mathrm{D} / \mathrm{H})_{\text {radical-free }}$ $\times\left(1-\mathrm{H}_{\text {radicals }} / \mathrm{H}_{\text {total }}\right)$; with $(\mathrm{D} / \mathrm{H})_{\text {bulk }}=300 \times 10^{-6}$ from Robert and Epstein $(1982),(\mathrm{D} / \mathrm{H})_{\text {radicals }}=15000 \times 10^{-6}$ from Gourier et al. (2008) and $\mathrm{H}_{\text {radicals }} / \mathrm{H}_{\text {total }}=3.6 \times 10^{-3}$ (Binet et al. 2002). Figure 1(a) shows a $\mathrm{D} / \mathrm{H}$ image that reveals the occurrence of distinct D-rich hotspots in Orgueil IOM with a $\mathrm{D} / \mathrm{H}$ ratio consistent with the predicted value for radical-rich regions ((D) $\left.\mathrm{H})_{\text {rad-rich }} \geqslant 570 \times 10^{-6}\right)$, indicating that organic radicals are responsible for the Deuterium enrichment detected as hot spots.

If we now use $(\mathrm{D} / \mathrm{H})_{\text {bulk }}$ and $(\mathrm{D} / \mathrm{H})_{\text {radical-free }}$ from isotopic imaging of Orgueil IOM (Figure 1) and $(\mathrm{D} / \mathrm{H})_{\text {radicals }}$ from pulsed EPR in the previous equation, the ratio $\mathrm{H}_{\text {radicals }} / \mathrm{H}_{\text {total }}$ can be determined and compared with the equivalent ratio obtained independently from EPR spectroscopy (Table 1). This time, $(\mathrm{D} / \mathrm{H})_{\text {radical-free }}$ is determined by applying a threshold to the isotopic images of Orgueil IOM. Only pixels that fall below this threshold are used to determine the average $(\mathrm{D} / \mathrm{H})_{\text {radical-free }}$. Because the D-rich hotspots are spatially well defined, the final result is not sensitive to reasonable variations in this threshold. We note that the inferred difference between $(\mathrm{D} / \mathrm{H})_{\text {bulk }}(223$ $\left.\times 10^{-6}\right)$ and $(\mathrm{D} / \mathrm{H})_{\text {radical-free }}$ lies between $25 \times 10^{-6}$ and $45 \times 10^{-6}$ (Table 1 ), consistent with calculations based on compound specific hydrogen isotopic composition (Remusat et al. 2006) and EPR (Gourier et al. 2008). With these numbers, the estimated average $\mathrm{H}_{\text {radicals }} / \mathrm{H}_{\text {total }}$ falls between $1.65 \times 10^{-3}$ and $2.87 \times 10^{-3}$, in agreement with the EPR data $\left(3.6 \times 10^{-3}\right)$ within the estimated uncertainties (see Table 1). Nevertheless, the calculated value for $\mathrm{H}_{\text {radicals }} / \mathrm{H}_{\text {total }}$ is slightly lower than the EPR determination. This is likely due to the fact that the $\mathrm{H}_{\text {radicals }} /$ $\mathrm{H}_{\text {total }}$ estimation obtained from EPR includes the contribution of the diradicaloids in Orgueil IOM, which represent $40 \%$ of the total organic radicals (Binet et al. 2004). However, these molecular species are not in a radical state below $130 \mathrm{~K}$ (Binet et al. 2004). This is due to a thermal change in the electron configuration of the diradicaloid resulting in a pairing of the electrons at low temperature. Thus at the very low temperature at which the isotopic exchange is supposed to take place $(T \leqslant$ $40 \mathrm{~K}$; see later in the discussion), the diradicaloids should be much less reactive and less sensitive to isotopic exchange than the monoradicals. Then, it seems reasonable to expect that only monoradicals, which are the only radical species prevailing at low temperature, are D-rich. Their concentration can be estimated to $(1-0.4) \times 3.6 \times 10^{-3}=2.16 \times 10^{-3}$. Then, if we consider only monoradicals, the EPR estimation falls exactly between the two extreme calculated values. Moreover, we may underestimate the radical abundance as very small radicalrich areas, defining D-rich hot spots smaller than the spatial resolution of the NanoSIMS (i.e., $<75 \mathrm{~nm}$ ), may occur. Such small D-rich areas are not detectable with the NanoSIMS and would correspond to a diffuse distribution of radicals in the IOM.

However, hotspots have maximum $\mathrm{D} / \mathrm{H}$ ratios up to $700 \times$ $10^{-6}$, i.e., are much less enriched in deuterium than the radicals they contain, indicating that even they are mixtures of radicalrich and radical-free organic matter. The relative proportion of this mixing can also be estimated. Mass balance using the radical EPR D/H ratio $\left(15000 \pm 5000 \times 10^{-6}\right)$ and the hotspot $\mathrm{D} / \mathrm{H}$ ratio allow us to determine $\left(\mathrm{H}_{\text {radicals }} / \mathrm{H}_{\text {total }}\right)_{\text {hotspot }}$ from which an average ratio $\left(\mathrm{H}_{\text {radicals }} / \mathrm{H}_{\text {total }}\right)_{\text {hotspot }} /\left(\mathrm{H}_{\text {radicals }} / \mathrm{H}_{\text {total }}\right)_{\text {bulk }}=6.5$ is obtained. This ratio indicates that the radical concentration in the hotspots is, on average, 6.5 times higher than if the radicals were homogeneously distributed in bulk IOM (Binet et al. 2002). A similar ratio of about 6 in Orgueil IOM was obtained from EPR data (Binet et al. 2002), in excellent agreement with the above estimate (Figure 2).

\section{COSMOCHEMICAL IMPICATIONS}

From these calculations, it is clear that the organic radicals account for the entire excess of deuterium (relative to the bulk 


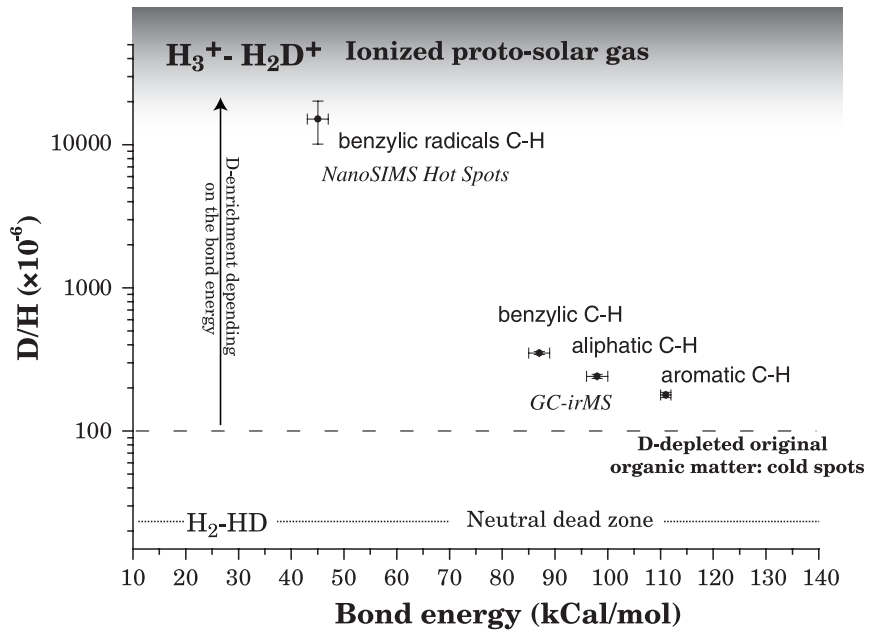

Figure 3. $\mathrm{D} / \mathrm{H}$ isotopic ratio vs. $\mathrm{C}-\mathrm{H}$ bond energy among different molecular components in Orgueil IOM. The observed trend is the inferred result of an isotopic exchange reaction between D-poor organic solids and D-rich gaseous molecules $\left(\mathrm{H}_{2} \mathrm{D}^{+}, \mathrm{HD}_{2}{ }^{+} \ldots\right)$, most likely taking place in the outer and relatively cold regions of the proto-planetary disk.

value) associated with the D-rich hotspots. The present study thus connects the D-isotopic heterogeneity at micrometer scale (occurrence of hot spots) to heterogeneity at molecular scale by identifying the molecular species that constitutes the D-rich hot spots. It also raises the question of the origin of the organic radicals, and their evolution. However, it must be noted that, despite their reactivity, organic radicals observed in Orgueil IOM survive boiling water at reflux for $48 \mathrm{hr}$ at the beginning of the IOM extraction procedure (Remusat et al. 2005b). This implies a preservation process that is not yet fully understood, but which prevents radicals from being completely destroyed by hot water during the chemical extraction procedures and on the parent body during the hydrothermal event(s) that affected Orgueil parent body (Bunch \& Chang 1980). Organic synthesis in irradiated environment is likely responsible for the formation of organic radicals and radiations may also induce ion/molecule reactions that could lead to the large fractionations observed in the radicals compared to radical-free IOM.

Figure 3 shows a negative correlation between $\mathrm{C}-\mathrm{H}$ bond energy and $\mathrm{D} / \mathrm{H}$ ratio of different molecular IOM species. This correlation tends to link the molecular structure to the isotopic ratio. The isotopic distribution in IOM is likely related to different behavior of different $\mathrm{C}-\mathrm{H}$ bonds more than to a physical mixing between different reservoirs with different compositions. It must be noted that if this trend appears, unless being fortuitous, this means that the molecular structure was formed first and that the isotopic exchange is a secondary process. This observation has been interpreted as the result of an isotopic exchange between D-poor organic matter and a Drich-ionized gas (Remusat et al. 2006; Gourier et al. 2008). The IOM from Orgueil also contains so-called coldspots, defined as regions with $\mathrm{D} / \mathrm{H}$ ratios more than $2 \sigma$ below the $(\mathrm{D} / \mathrm{H})_{\text {bulk }}$ (Figure 1). These coldspots have $\mathrm{D} / \mathrm{H}$ ratios of $101( \pm 18) \times$ $10^{-6}-150( \pm 15) \times 10^{-6}$ and could represent the $\mathrm{D}$-poor organic precursor with a $\mathrm{D} / \mathrm{H}$ ratio close to the protosolar hydrogen $(25$ $\left.\pm 5 \times 10^{-6}\right)$.

There are essentially two environments where this deuterium enrichment can take place: (1) the interstellar medium or (2) the proto-planetary disk around the young Sun. Conventionally, deuterium enrichments observed in IOM from primitive meteorites or in interplanetary dust particles (IDPs) have been ascribed to ion-molecule reactions, taking place at low temperature in cold and dense molecular clouds (Yang \& Epstein 1983; Messenger 2000; Sandford et al. 2001). In this scenario, organic molecules are formed by sequential reactions such as: (1) $\mathrm{H}_{2}+\mathrm{C}^{+} \rightarrow \mathrm{CH}^{+}+\mathrm{H}$, (2) $\mathrm{H}_{2}+\mathrm{CH}^{+} \rightarrow \mathrm{CH}_{2}^{+}+\mathrm{H}$, (3) $\mathrm{H}_{2}+\mathrm{CH}_{2}{ }^{+} \rightarrow \mathrm{CH}_{3}{ }^{+}+\mathrm{H}$ (Millar et al. 1987; Hasegawa et al. 2000 ). Ions are produced by the interaction between molecules and interstellar UV radiation or cosmic rays. The size of these organic molecules increases through subsequent carbon addition (Woods et al. 2003). The deuterium enrichment takes place via $\mathrm{HD}+\mathrm{H}_{3}{ }^{+} \rightarrow \mathrm{H}_{2}+\mathrm{H}_{2} \mathrm{D}^{+}$, followed by reactions such as $(-\mathrm{CH})_{\text {organics }}+\mathrm{H}_{2} \mathrm{D}^{+} \rightarrow(-\mathrm{CD})_{\text {organics }}+\mathrm{H}_{3}{ }^{+}$, with $(-\mathrm{CH})_{\text {organics }}$ representing the gaseous molecules that are potential precursors of the IOM.

Models in which meteoritic IOM has an interstellar origin assume that the IOM was introduced into the proto-planetary disk, either during the collapse of the parental molecular cloud or by a late infall of materials onto the disk. In both cases, IOM was subsequently incorporated into primitive meteorite parent bodies. One difficulty with such a scenario is that, with the exception of a few hotspots in IOM (Busemann et al. 2006), the $\mathrm{D} / \mathrm{H}$ ratios measured in the IOM (Wang et al. 2005; Remusat et al. 2006) at the molecular level, along with organic moieties recovered in other solar system objects (Robert et al. 2000; Sandford et al. 2006), are substantially lower, by at least one order of magnitude, than those observed in the gaseous interstellar organic molecules (the $\mathrm{D} / \mathrm{H}$ ratio of organics trapped on grain surfaces in the interstellar medium is not known). In order to explain this discrepancy, it has been proposed that interstellar organic materials have exchanged their deuterium with the molecular $\mathrm{H}_{2}$ gas of the proto-planetary disk (having a $\left.\mathrm{D} / \mathrm{H}=25( \pm 5) \times 10^{-6}\right)$, thereby lowering their $\mathrm{D} / \mathrm{H}$ ratio, before incorporation into planetesimals (Drouart et al. 1999; Mousis et al. 2000; Hersant et al. 2001). If organic molecules are synthesized in molecular cloud as previously described, then it should be postulated that the process would produce small molecules enriched in $\mathrm{D}$ and that these short compounds would further polymerize to form the complex network of the IOM. Then, to get the isotopic composition we observed, IOM should exchange with D-poor reservoir (nebular $\mathrm{H}_{2}$ or meteoritic water on the parent body) as a secondary process. However, the negative correlation between $\mathrm{D} / \mathrm{H}$ ratio and $\mathrm{C}-\mathrm{H}$ bond energy (Figure 3) argues against such a scenario, which would result in the opposite correlation. Moreover, irradiation experiments on IDPs indicate that in dense ISM, organic matter should lose its $\mathrm{H}$ (and $\mathrm{D}$ ) by UV irradiation or high energy $\mathrm{H}$ bombardment (Muñoz Caro et al. 2006). This leads to the conclusion that any D-isotopic signature on interstellar organic matter might be lost before the formation of the solar nebula. Processes in the protoplanetary disk around the young Sun are therefore explored.

In the midplane zone of a proto-planetary disk, the relatively high temperatures $(T>400 \mathrm{~K})$ and pressures $\left(P>10^{-6} \mathrm{~atm}\right)$ favor the occurrence of thermal reactions (Fegley 1999) that produce organic compounds from reactions such as $3 \mathrm{H}_{2}+$ $\mathrm{CO} \rightarrow \mathrm{CH}_{4}+\mathrm{H}_{2} \mathrm{O}$. The $P, T$ conditions of the midplane kinetically limit the deuterium enrichment of organic molecules through thermal reactions such as $\mathrm{HD}+\mathrm{CH}_{4} \rightarrow \mathrm{H}_{2}+\mathrm{CH}_{3} \mathrm{D}$ (Fegley 1999). Furthermore, UV radiation and cosmic rays do not penetrate to the mid-plane of the disk, and D-rich gaseous species are therefore not produced there. In these regions of the disk, the $\mathrm{D} / \mathrm{H}$ ratio of organic molecules could theoretically reach at most $120 \times 10^{-6}$ (Lécluse \& Robert 1994), consistent 
with the $\mathrm{D} / \mathrm{H}$ ratio of the coldspots (Figure $1(\mathrm{~A})$ ). This value drops to $35 \times 10^{-6}$ if a turbulent nebula with a temperature gradient is considered (Drouart et al. 1999). In contrast, in the outer zones of the disk where ionization is more effective (Markwick et al. 2002), highly D-enriched isotopologues of $\mathrm{H}_{3}{ }^{+}$are predicted to exist (Ceccarelli \& Dominik 2005). Indeed, astrophysical models and observations (Ceccarelli \& Dominik 2005) indicate that abundant $\mathrm{H}_{2} \mathrm{D}^{+}, \mathrm{HD}_{2}{ }^{+}$, and even $\mathrm{D}_{3}{ }^{+}$molecules can be produced in the outer regions of protoplanetary disks. The temperature corresponding to a $\mathrm{D} / \mathrm{H}$ ratio of $15000 \times 10^{-6}$ in the $\mathrm{H}_{3}{ }^{+}$molecule (through the reaction HD $+\mathrm{H}_{3}{ }^{+} \rightarrow \mathrm{H}_{2}+\mathrm{H}_{2} \mathrm{D}^{+}$) is about $35 \mathrm{~K}$ (using $232 \mathrm{~K}$ for the most recent estimate of the exoergicity of the reaction; Roueff et al. 2007). This temperature is obtained in the outer regions of the disk at distances from the Sun corresponding to the present day orbits of Kuiper Belt objects.

Organic grains from the inner and warm regions of the disk, characterized by low $\mathrm{D} / \mathrm{H}$ ratios, could be brought (e.g., by turbulence or by bi-polar outflows) to the cold outer regions of the disk during the early stages of the protosolar nebula. Exposed to UV irradiations, this proto-IOM should undergo radical production and should be exposed to the ionized molecular hydrogen, enriched in deuterium. The deuteration reactions should result in the $\mathrm{D} / \mathrm{H}$ versus $\mathrm{C}-\mathrm{H}$ bond energy correlation observed in Figure 3. Indeed, since the isotopic fractionation factors between the different $\mathrm{C}-\mathrm{H}$ bonds are negligible compared to the difference in the $\mathrm{D} / \mathrm{H}$ ratios between $\mathrm{C}-\mathrm{H}$ and $\mathrm{D}$-rich ions (up to two orders of magnitude according to Figure 3), the correlation reflects only the homogenization rate between the deuteriumrich source and the $\mathrm{C}-\mathrm{H}$ bonds. All the other parameters for the deuteration rates being equal for the different $\mathrm{C}-\mathrm{H}$ bonds; the rate constant for the statistical isotopic redistribution between chemical species is controlled by the binding energies, i.e., by the energies involved to break the chemical bond that yields the replacement of -H by -D. Of course, unexpected quantum effect(s) specific to aromatics, aliphatic or benzylic bonds are not considered-but unexpected. Such an assumption is under the course of an experimental verification. This scenario is consistent with the conclusion by Nuth et al. (2008) that selfperpetuating high-temperature catalytic reactions may occur in protostellar nebulae, leading to an important production of organic matter that is then carried to cold regions by turbulence, where it can condense to form organic grains thoroughly accreted on planetesimals.

In this model, the D-rich organic radicals in meteorites provide direct evidence for the occurrence of D-rich molecular ions in the gas phase of the proto-planetary disk around the Sun and IOM is likely a protosolar product. Such a prediction is testable by astronomical observations of disks around young stellar objects. Our model needs numerical parameters, especially exchange rates for each $\mathrm{C}-\mathrm{H}$ bond, to be better constrained and to be compared with other models of solar nebula early evolution. For instance, it would be useful to check if the time needed to reach the predicted fractionations is reasonable.

The deuterium content in the IOM of different class of chondrites has been studied by Alexander et al. (2007). If there is a possible trend for carbonaceous chondrites, potentially linking the isotopic composition to the parent body history, then isotopic composition of ordinary chondrites is too heavy to fit this model. As the molecular structure of ordinary chondrites is poorly constrained, it is impossible to relate Alexander et al. data to our model. Furthermore, it seems unlikely that the occurrence of more hot spots rich in $\mathrm{D}$ (whatever their origin) could explain the high $\mathrm{D} / \mathrm{H}$ values for ordinary chondrites, as the bulk values for some samples are in the same range of the values determined for the hot spots of Orgueil and Murchison. If the organic radicals are present in high concentration in the IOM of ordinary chondrites, then they may explain the compositions measured. Unfortunately, due to sample availability, the determination of the radical content of IOM from any ordinary chondrites was not yet attempted. So if, as we expect, the D-isotopic composition is controlled by the molecular structure, more measurements are required on the structure of IOM of ordinary chondrites and on its deuterium distribution to determine if our model can reconcile observation over the organic constituents of a wide range of chondrites. Moreover, the preservation of the Disotopic anomaly in the hydrated carbonaceous chondrites is still enigmatic, as exchange with water and clay minerals on the parent body should have likely erased it in a few millions years (Sessions et al. 2004).

Other D-rich organic molecules are the products of ionmolecule reactions (DCN is an emblematic example of this ion chemistry). Observations of cometary $\mathrm{HCN}$ have yielded $\mathrm{D} / \mathrm{H}$ ratios of $2000 \times 10^{-6}$, i.e., within the range of $\mathrm{D} / \mathrm{H}$ ratios defined by the chondritic IOM moieties. Labile organic components with $\mathrm{C} / \mathrm{N}$ ratios close to unity were also observed among materials brought back by the Stardust sample return mission to Comet 81P/Wild 2 (Sandford et al. 2006). The nitrogen isotopic composition of these $\mathrm{HCN}$ derived polymers is close to that inferred for the solar nebula (McKeegan et al. 2006; Meibom et al. 2007) indicating a local origin for the CN group, implying that the deuterium enrichment of HCN observed in comets is the result of a process occurring in the protosolar nebula. The protosolar disk origin proposed here therefore reconciles data from IOM in primitive carbonaceous chondrites with astronomical observations of comets. It is also consistent with the recent observation of an active organic chemistry in the region of planet formation in young circumstellar disks (Carr \& Najita 2008).

The NanoSIMS facility at the Museum National d'Histoire Naturelle in Paris was established through funds from CNRS, Region Ile de France, the French Ministry for Research and Museum National d'Histoire Naturelle. This work was supported by the Agence Nationale de la Recherche (ANR). We are grateful to the anonymous referee for his comments that improved this paper. John Eiler is also thanked for helpful discussions on this manuscript.

\section{REFERENCES}

Alexander, C. M. O. D., Fogel, M., Yabuta, H., \& Cody, G. D. 2007, Geochim. Cosmochim. Acta, 71, 4380

Binet, L., Gourier, D., Derenne, S., \& Robert, F. 2002, Geochim. Cosmochim. Acta, 66, 4177

Binet, L., Gourier, D., Derenne, S., Robert, F., \& Ciofini, I. 2004, Geochim. Cosmochim. Acta, 68, 881

Bonal, L., Bourot-Denise, M., Quirico, E., Montagnac, G., \& Lewin, E. 2007, Geochim. Cosmochim. Acta, 71, 1605

Bunch, T. E., \& Chang, S. 1980, Geochim. Cosmochim. Acta, 44, 1543

Busemann, H., Young, A. F., Alexander, C. M. O. D., Hoppe, P., Mukhopadhyay, S., \& Nittler, L. R. 2006, Science, 312, 727

Carr, J. S., \& Najita, J. R. 2008, Science, 319, 1504

Ceccarelli, C., \& Dominik, C. 2005, Astron. Astrophys., 440, 583

Drouart, A., Dubrulle, B., Gautier, D., \& Robert, F. 1999, Icarus, 140, 129

Fegley, B. 1999, Space Sci. Rev., 90, 239

Gardinier, A., Derenne, S., Robert, F., Behar, F., Largeau, C., \& Maquet, J. 2000, Earth Planet. Sci. Lett., 184, 9 
Garvie, L. A. J., \& Buseck, P. R. 2004, Earth Planet. Sci. Lett., 224, 431

Gourier, D., Robert, F., Delpoux, O., Binet, L., Vezin, H., Moissette, A., \& Derenne, S. 2008, Geochim. Cosmochim. Acta, 72, 1914

Hasegawa, T., Volk, K., \& Kwok, S. 2000, Astrophys. J., 532, 994

Hayatsu, R., Winans, R. E., Scott, R. G., McBeth, R. L., Moore, L. P., \& Studier M. H. 1980, Science, 207, 1202

Hersant, F., Gautier, D., \& Hure, J. M. 2001, Astrophys. J., 554, 391

Kerridge, J. F. 1983, Earth Planet. Sci. Lett., 64, 186

Lécluse, C., \& Robert, F. 1994, Geochim. Cosmochim. Acta, 58, 2927

Lodders, K. 2003, Astrophys. J., 591, 1220

Markwick, A. J., Ilgner, M., Millar, T. J., \& Henning, T. 2002, Astron. Astrophys., 385, 632

McKeegan, K. D., et al. 2006, Science, 314, 1724

Meibom, A., Krot, A. N., Robert, F., Mostefaoui, S., Russell, S. S., Petaev, M. I., \& Gounelle, M. 2007, Astrophys. J., 656, L33

Messenger, S. 2000, Nature, 404, 968

Millar, T. J., Leung, C. M., \& Herbst, E. 1987, Astron. Astrophys., 183, 109

Mousis, O., Gautier, D., Bockelee-Morvan, D., Robert, F., Dubrulle, B., \& Drouart, A. 2000, Icarus, 148, 513

Muñoz Caro, G. M., et al. 2006, Astron. Astrophys., 459, 147

Nakamura-Messenger, K., Messenger, S., Keller, L. P., Clemett, S. J., \& Zolensky, M. E. 2006, Science, 314, 1439

Nuth, J. A., III, Johnson, N. M., \& Manning, S. 2008, ApJL, 673, L225

Pizzarello, S., Cooper, G. W., \& Flynn, G. J. 2006, in Meteorites and the Early Solar System II, ed. D. Lauretta \& H. Y. J. J. McSween (Tucson, USA: Univ. of Arizona Press), 625

Qi, C., Wilner, D. J., Aikawa, Y., Blake, G. A., \& Hogerheijde, M. R. 2008, ApJ, 681,1396
Remusat, L., Derenne, S., \& Robert, F. 2005a, Geochim. Cosmochim. Acta, 69, 4377

Remusat, L., Derenne, S., Robert, F., \& Knicker, H. 2005b, Geochim. Cosmochim. Acta, 69, 3919

Remusat, L., Le Guillou, C., Rouzaud, J.-N., Binet, L., Robert, F., \& Derenne, S. 2008, Meteorit. Planet. Sci., 43, 1099

Remusat, L., Palhol, F., Robert, F., Derenne, S., \& France-Lanord, C. 2006, Earth Planet. Sci. Lett., 243, 15

Robert, F., \& Epstein, S. 1982, Geochim. Cosmochim. Acta, 46, 81

Robert, F., Gautier, D., \& Dubrulle, B. 2000, Space Sci. Rev., 92, 201

Robert, F., Mostefaoui, S., Aléon, J., Derenne, S., Remusat, L., \& Meibom, A 2006, in 37th Lunar and Planetary Science Conference, NanoSIMS H, C, N and O-isotopic study of insoluble organic matter in Murchison, 1301

Roueff, E., Herbst, E., Lis, D. C., \& Phillips, T. G. 2007, ApJ, 661, L159

Sandford, S., Bernstein, M. P., \& Dworkin, J. P. 2001, Meteorit. Planet. Sci., 36, 1117

Sandford, S. A., et al. 2006, Science, 314, 1720

Sephton, M. A., \& Gilmour, I. 2000, ApJ, 540, 588

Sephton, M. A., Love, G. D., Watson, J. S., Verchovsky, A. B., Wright, I. P., Snape, C. E., \& Gilmour, I. 2004, Geochim. Cosmochim. Acta, 68, 1385

Sessions, A. L., Sylva, S. P., Summons, R. E., \& Hayes, J. M. 2004, Geochim. Cosmochim. Acta, 68, 1545

Wang, Y., Huang, Y., Alexander, C. M. O. D., Fogel, M., \& Cody, G. 2005, Geochim. Cosmochim. Acta, 69, 3711

Woods, P. M., Millar, T. J., Herbst, E., \& Zijlstra, A. A. 2003, Astron. Astrophys., 402, 189

Yang, J., \& Epstein, S. 1983, Geochim. Cosmochim. Acta, 47, 2199 